\title{
TORSION OF PARAOVARIAN CYST RESULTING IN SECONDARY TORSION OF OVARY
}

Alka Dani ${ }^{1}$, Sudha R. Gandi², Jeehan ${ }^{3}$

\section{HOW TO CITE THIS ARTICLE:}

Alka Dani, Sudha R. Gandi, Jeehan. "Torsion of Paraovarian CYST Resulting in Secondary Torsion of Ovar". Journal of Evolution of Medical and Dental Sciences 2015; Vol. 4, Issue 28, April 06; Page: 4901-4903, DOI:10.14260/jemds/2015/712

ABSTRACT: Paraovarian cysts account for $10 \%$ of all adnexal masses. Small POC (Paraovarian Cyst) are common but large POC are rare and very rarely they undergo torsion. Fallopian tube and ovary being in close proximity to POC also undergo torsion along with it. It is usually found in child bearing age. High index of suspicion \& prompt treatment is required to salvage the fallopian tube and ovary in such cases. We report a rare case of twisted paraovarian cyst with secondary torsion of ovary around infundibulopelvic ligament.

KEYWORDS: Torsion of Ovary, paraovarian cyst, torsion of adnexal mass.

INTRODUCTION: Paraovarian cyst arise from the mesothelium and presume to be vestigeal remnant of mullerian and wolffian duct.[1,2] It accounts for $10 \%$ of all adnexal masses ${ }^{[3]}$ but usually are small and asymtomatic. A large POC is uncommon. It lies in broad ligament near to ovary and fallopian tube is stretched over it. POC is benign, unilocular, thin walled and contains clear fluid. The cyst wall is lined by a single layer of cuboidal epithelium and fibrous tissue. Torsion of POC is very rare.[4] Fallopian tube and ovary being in close proximity to POC can also undergo torsion along with it.

CASE REPORT: A 22 years old unmarried girl presented to emergency unit with complaints of pain in lower abdomen and 3 episodes of vomitings for 6-8 hours. Pain was more in left iliac fossa with sudden onset, sharp, non-radiating and with no relieving factor. There was no history of bleeding per vaginum, diarrhoea, constipation, urinary problems, fever or any other medical illness. Her menses were regular with normal flow. She had her last menses 24 days back.

On general examination the patient was conscious, pulse rate- $102 /$ minute, temperature was normal, BP-120/80 mm of $\mathrm{Hg}$, cardiovascular and respiratory system were normal. On abdominal examination tenderness and muscle guarding were present in lower abdomen. On per rectal examination a cystic mass felt on left side of uterus which was very tender. On investigation, her urine pregnancy test was negative. The routine urine and blood tests were normal. Abdominal ultrasound scan showed bulky left ovary with absent venous flow on colourdoppler study and right simple ovarian cyst.

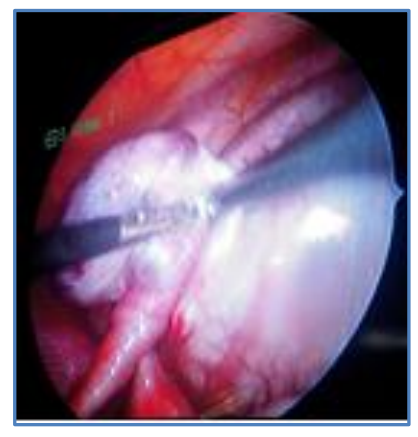

Fig. 1: Ovary \& paraovarian cyst 


\section{CASE REPORT}

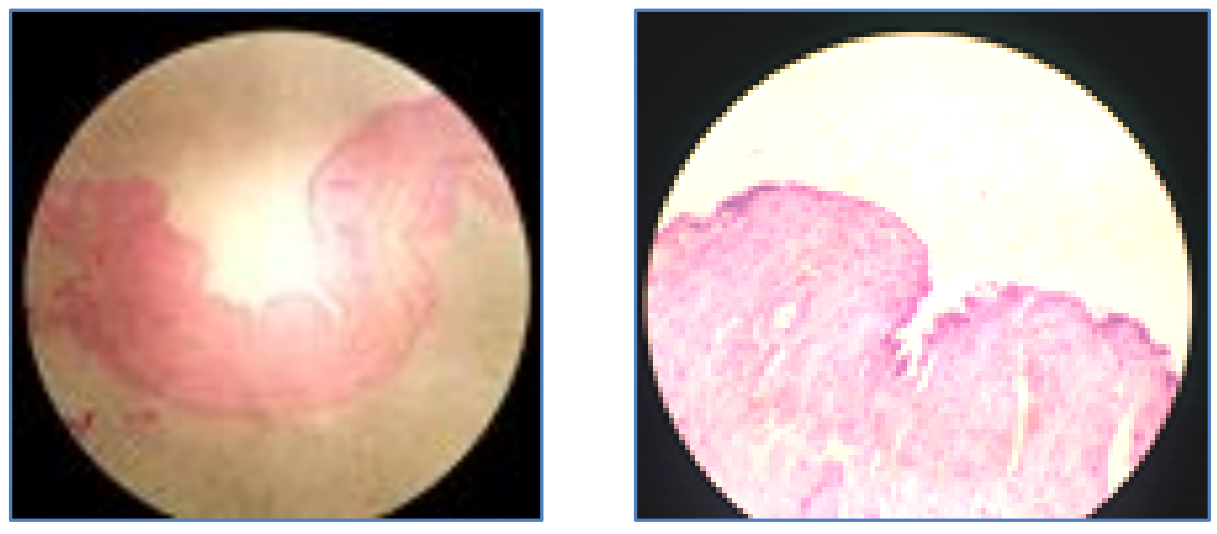

Fig. 2: Paraovarian cyst wall

An emergency diagnostic laparoscopy followed by mini laparotomy was done. Laparoscopy revealed a normal sized uterus with a large paraovarian cyst of $\sim 6 \mathrm{~cm} * 5 \mathrm{~cm}$ in size which was twisted around infundibulopelvic ligament on left side. Left fallopian tube was odematous and overstretched over it. Left ovary was bulky with dusky, cyanotic hue due to torsion around infundibulopelvic ligament (Fig. 1) On right side, a ruptured haemorrhagic cyst of ovary of $\sim 3^{*} 4 \mathrm{~cm}$ in size was present with minimal blood in pouch of douglas. POC was puntured and fluid was drained with suction cannula laparoscopically. Detortion of ovary and POC was done. Ovary resumed its normal colour. Mini laparotomy was done to enucleate and remove cyst wall. Peritoneal lavage was done. Post-operative period was uneventful. Histopathological report showed paraovarian cyst wall (Fig. 2) lined by cuboidal epithelial and fibrous tissues.

DISCUSSION: Torsion of paraovarian cyst is more common in child bearing age and three times more common during pregnancy.[5] As cyst lies in broad ligament and it has no pedicle of its own, when it undergoes torsion fallopian tube and ovary being close to it also twist along with it. It is difficult to differentiate between paraovarian cyst and ovarian cyst clinically and on sonoscan. CT scan and MRI are more useful but can delay the treatment. High index of suspicion and prompt surgery is recommended to salvage the fallopian tube and ovary. Several authors advocate detorsion of the pedicle with preservation of adnexal structures. ${ }^{[6,7]}$ In this case it was possible to preserve the ovary after detorsion of infundibulopelvic ligament.

\section{REFERENCES:}

1. Kiseli M, Caglar GS, Cangez SD, Karadag D, Yilmaz MD; Clinical diagnosis and complications of paratubal cyst: Review of the literature and report of uncommon cases. Arch gynecol Obstet $2010 ; 285 ; 1563-69$.

2. Hasou Y, Higashijima T, Mitamura T; Torsion of paraovarian cyst - Report of two cases. Kurume Med J. 1991; 38 (1); 39 - 43.

3. Barloon TJ; Brown BP; Abu-Yusuf MM, Warnock NG. Paraovarian and paratubal cysts: preoperative diagnosis using transabdominals onography. J Clin Ultrasound 1996; 24: 22-117.

4. Valvi Durga; Parulekar SV; Fernandez Gwendolyn: torsion of paraovarion cyst in pregnancy: JPOG 2014 Vol. 1No. 10. 


\section{CASE REPORT}

5. Puri N, Jain K, Negi K. Torsion of Paraovarian cyst: A cause of acute abdomen. Indian J Mad Sci 2003; 57: 2-361.

6. Yousef AF, Fayad MM, Shafeek MA. Torsion of the fallopian tube; A clinic-pathological study, Acta Obstet Gynec Scand 1962; 41; 292-309.

7. Hibbard LT, Adenaxal torsion. Am J ObstetGynecol 1985; 152: 456-61.

\section{AUTHORS:}

1. Alka Dani

2. Sudha R. Gandi

3. Jeehan

\section{PARTICULARS OF CONTRIBUTORS:}

1. Assistant Professor, Department of Obstetrics \& Gynaecology, Dr. D. Y. Patil Medical College, Hospital \& Research Center, Nerul, Navi Mumbai.

2. Associate Professor, Department of Obstetrics \& Gynaecology, Dr. D. Y. Patil Medical College, Hospital \& Research Center, Nerul, Navi Mumbai.

FINANCIAL OR OTHER

COMPETING INTERESTS: None
3. Registrar, Department of Obstetrics \& Gynaecology, Dr. D. Y. Patil Medical College, Hospital \& Research Center, Nerul, Navi Mumbai.

\section{NAME ADDRESS EMAIL ID OF THE} CORRESPONDING AUTHOR:

Dr. Alka Dani,

Flat No. 204, Chaurang CHS Ltd,

Plot No. 4, Sector 16, Sanpada,

Navi Mumbai-400705.

E-mail: alka.dani@gmail.com

Date of Submission: 23/03/2015.

Date of Peer Review: 24/03/2015.

Date of Acceptance: 25/03/2015.

Date of Publishing: 06/04/2015. 